\title{
FOLATOS EM BRÓCOLIS CONVENCIONAL E ORGÂNICO E PERDAS NO PROCESSO DE COCÇÃO EM ÁGUA
}

\author{
Juliana Azevedo Lima-Pallone* \\ Centro de Ciências Exatas, Ambientais e de Tecnologias, Faculdade de Química, Pontifícia Universidade Católica de Campinas, \\ Rodovia Dom Pedro I, km 136, 13086-900 Campinas - SP, Brasil \\ Rodrigo Ramos Catharino e Helena Teixeira Godoy \\ Departamento de Ciência de Alimentos, Faculdade de Engenharia de Alimentos, Universidade Estadual de Campinas, CP 6121, \\ 13083-970 Campinas - SP, Brasil
}

Recebido em 29/1/07; aceito em 20/9/07; publicado na web em 19/3/08

\begin{abstract}
FOLATES IN CONVENTIONAL AND ORGANIC BROCCOLI AND LOSSES DURING COOKING. Broccoli is a vegetable consumed in many countries and a possible source of folates, which are water-soluble vitamins active during DNA synthesis. The folates found in the samples analyzed were 5-methyltetrahydrofolate and 5-formyltetrahydrofolate. The vitamin content varied between 413.7 and $742.2 \mu \mathrm{g} / 100 \mathrm{~g}$ for 5-methyltetrahydrofolate and from 4.8 to $12.8 \mu \mathrm{g} / 100 \mathrm{~g}$ for 5 -formyltetrahydrofolate. In organic broccoli the amount of 5-methyltetrahydrofolate was significantly higher than in the same vegetable cultivated by traditional methods, for the commercial samples analyzed. The losses of these folates after cooking in water were of approximately $68 \%$, most of it $(53 \%)$ found in the cooking water.
\end{abstract}

Keywords: folates; broccoli; cultivation type and cooking.

\section{INTRODUÇÃO}

Nos últimos 30 anos, o avanço nos conhecimentos tornou evidente que os folatos apresentam importância vital para a saúde humana. São essenciais como cofatores na síntese de DNA e neurotransmissores, além de participarem do metabolismo de aminoácidos. A ingestão de níveis adequados de folatos é requerida para o metabolismo normal, divisão celular, funções neurais e crescimento. Gestantes devem aumentar o aporte de folatos na dieta a fim de prevenir malformações congênitas como espinha bífida e outros defeitos no tubo neural de fetos. ${ }^{1-3} \mathrm{~A}$ ingestão de quantidade abaixo de $240 \mu \mathrm{g}$ folato/dia também está associada ao aumento de risco de partos prematuros e recém-nascidos com baixo peso. ${ }^{4}$

A deficiência dessa vitamina também está relacionada ao risco de câncer de cólon, ${ }^{5}$ doenças cardiovasculares ocasionadas por elevados níveis de homocisteína ${ }^{6,7}$ e desordens cerebrais como depressão e mal de Alzheimer., ${ }^{8,9}$

Dentre as principais fontes de folatos, os vegetais podem ser considerados as mais importantes. ${ }^{10}$ A grande variação observada nos níveis da vitamina encontrados nesses alimentos (Quadro 1), pode ser devida aos diferentes métodos de análise utilizados nas determinações, mas, também, a fatores que influenciam no crescimento e desenvolvimento da planta.

Nos vegetais os derivados de folatos e sua distribuição nas diferentes porções são afetados pela luz, já que a síntese da vitamina ocorre na fotorespiração. ${ }^{11,12}$ Scott et al. ${ }^{13}$ também apontam o grau de maturação como um parâmetro importante no teor de folatos nesse tipo de alimento, já que eles participam do processo de divisão celular e, portanto, a sua quantidade é maior nos tecidos em divisão que nos tecidos já maduros, onde não há ocorrência desse processo. Minerais como magnésio e potássio também são bastante importantes na produção de folatos pelos vegetais, participando de uma das etapas da biossíntese dessa vitamina. ${ }^{13,17}$

*e-mail: julianalima@puc-campinas.edu.br
Quadro 1. Folatos totais em brócolis

\begin{tabular}{lc}
\hline Concentração de folatos totais $(\mu \mathrm{g} / 100 \mathrm{~g})$ & Ref. \\
\hline 866 & 14 \\
$174 \pm 14$ & 15 \\
$65 \pm 2$ & 16 \\
114 & 17 \\
102 & 18 \\
100 & 10 \\
133 & 19 \\
169 & 20 \\
189 & 21 \\
\hline
\end{tabular}

Atualmente, o cultivo de vegetais, incluindo brócolis, tem sido realizado pelos métodos convencionais e também por agricultura orgânica, o que poderia acarretar em alterações na concentração de folatos. Porém, estudos avaliando a influência do tipo de cultivo no teor da vitamina não foram encontrados na literatura.

A degradação de vitaminas depende de condições específicas durante o processo culinário, como temperatura, presença de oxigênio, umidade, luz, pH e a duração do tratamento térmico. ${ }^{10,22}$ Os folatos, como muitas outras vitaminas hidrossolúveis, são muito mais sujeitos a perdas por lixiviação, em alimentos cozidos em água, que à degradação química.

Leichter et al..$^{20}$ examinaram o processo de lixiviação de folatos durante o cozimento (10 min em água em ebulição) para vários vegetais e observaram que entre 22 e $84 \%$ da quantidade inicial da vitamina foi para a água de cozimento. Os mesmos autores afirmaram ainda que a soma do teor de folatos encontrado na água de cozimento com a quantidade da vitamina retida no vegetal é equivalente ao total de folatos presente no vegetal cru. Para brócolis, apenas $38 \%$ do teor de folatos foi retido no vegetal. Já Klein et al. ${ }^{23}$ relataram $50 \%$ de retenção dos folatos em brócolis, após cozimento em água. Esses resultados sugerem ser a extração aquosa, e não a 
oxidação ou degradação térmica, a maior responsável pelas perdas de folatos durante o cozimento. Os dados foram obtidos com a utilização de método microbiológico. Stea et al. ${ }^{14}$ analisaram a retenção de folatos em brócolis cozidos e utilizados para consumo em serviços de larga escala, como hospitais e escolas, e concluíram que $24,5 \%$ da vitamina foi perdida, após cozimento em água. Os autores aplicaram uma metodologia utilizando cromatografia líquida de alta eficiência para obtenção dos resultados.

O objetivo do presente trabalho foi, portanto, determinar os folatos presentes em brócolis comercializados na cidade de Campinas, comparando a concentração da vitamina no vegetal cultivado de forma orgânica e convencional, além de verificar as perdas ocorridas após o cozimento em água, utilizando-se a técnica de cromatografia líquida de alta eficiência.

\section{PARTE EXPERIMENTAL}

\section{Produtos avaliados}

\section{Influência do tipo de cultivo}

Para o estudo da influência do tipo de cultivo foram adquiridos cinco diferentes lotes de brócolis (Brassica oleracea var. Italica Plenck), cultivados de forma convencional e por agricultura orgânica (certificado por IBD), disponíveis comercialmente na cidade de Campinas, Brasil. Os lotes foram diferenciados pela data de colheita, sendo cada lote representado por um maço de brócolis. As flores e talos foram finamente picados e homogeneizados, antes da retirada de amostra para análise. Todas as determinações foram feitas em triplicata.

\section{Influência do cozimento em água}

Para a avaliação da influência do cozimento em água no teor de folatos, cinco diferentes lotes de brócolis (Brassica oleracea var. Italica Plenck) foram adquiridos em estabelecimentos comerciais da cidade de Campinas-SP, diferenciados por distintas datas de colheita. Cada lote foi composto por um maço de brócolis. As flores e talos foram retirados, picados e homogeneizados, antes da retirada da amostra para análise. Dividiu-se o lote em duas porções, uma para a determinação de folatos no material cru e outra, no cozido.

Para os procedimentos de cozimento pesou-se 100,0 g de brócolis, adicionou-se 1,0 L de água e cozinhou-se em fogo médio por 5 min, após ebulição. Ao final do processo, o material foi escorrido e tanto o vegetal como a água de cozimento foram, imediatamente, esfriadas até a temperatura ambiente, para posterior análise. O processo de cozimento e as determinações de folatos foram realizados em triplicata, para cada lote.

\section{Determinação de umidade}

Utilizou-se o método por secagem em estufa (Nova Ética, 400/ $3 \mathrm{ND}, \mathrm{N}^{\circ}$ série $0766 / 00$ ) a temperatura de $105^{\circ} \mathrm{C}$, até peso constante (aproximadamente $3 \mathrm{~h}$ ). As determinações foram feitas em triplicata.

\section{Determinação dos folatos}

Reagentes

Os padrões de tetraidrofolato (THF), 5-metil-5,6,7,8tetraidrofolato de cálcio (5-metilTHF), 10-metil-ácidofólico (10metilAF), 5-formil-5,6,7,8-tetraidrofolato de cálcio (5-formilTHF), 10-formil-ácidofólico (10-formilAF) foram adquiridos do Laboratório Dr. Schircks (Jona, Suíça). A acetonitrila grau cromatográfico, o ácido acético e o hidróxido de potássio, grau analítico, foram adquiridos da Merck, Brasil. O ácido tricloroacético, fosfato de sódio dibásico e fosfato de potássio monobásico, grau analítico, foram adquiridos da Synth, Brasil. A água utilizada no preparo das amostras e das fases móveis, foi purificada no sistema Milli-Q (Millipore). As fases móveis foram filtradas em filtros Millipore (HAWP e FHLP 04700 Millipore), com poros de $0,45 \mu \mathrm{m}$ de diâmetro.

\section{Equipamento}

Utilizou-se um cromatógrafo Agilent Technologies, série 1100, com injetor automático com capacidade de 1 a $100 \mu \mathrm{L}$, degaseificador, bomba quaternária, equipado com detector de arranjo de diodos (DAD - UV-visível) e de fluorescência, dispostos em série. O software HPChemstation permitiu o melhor tratamento dos dados. A coluna Microsorb-MV, ODS-2, $5 \mu \mathrm{m}, 250 X 4,6 \mathrm{~mm}$ d.i. (Rainin Instrument Company) foi utilizada para o processo cromatográfico, protegida por uma coluna de guarda Bondesil $\mathrm{C}_{18}, 5 \mu \mathrm{m}, 10$ X 4,6 mm d.i (Varian).

\section{Metodologia analítica}

Para a análise dos folatos em brócolis, utilizou-se a metodologia desenvolvida por Catharino et al., ${ }^{24}$ adaptada para a matriz, que possibilitou a separação das diferentes formas da vitamina: tetraidrofolato (THF), 5-metiltetraidrofolato (5-metilTHF), 10metil-ácidofólico (10metil-AF), 5-formiltetraidrofolato (5formilTHF) e 10-formil-ácido fólico (10-formilAF).

Para a extração pesou-se $10,0 \mathrm{~g}$ de brócolis, após homogeneização total da amostra. Adicionou-se 50,0 mL de tampão fosfato, composto por fosfato de sódio dibásico $(0,25 \mathrm{~mol} / \mathrm{L}) /$ fosfato de potássio monobásico $(0,37 \mathrm{~mol} / \mathrm{L})$ e utilizou-se homogeneizador tipo Turatec. Retirou-se uma alíquota de $9,0 \mathrm{~mL}$ do extrato e adicionou-se $500 \mu \mathrm{L}$ de ácido tricloroacético (TCA), completando-se o volume final com tampão fosfato (balão volumétrico de $10,0 \mathrm{~mL}$ ). Seguiram-se então as etapas de filtração, a primeira em papel de filtro comum e a outra em membrana (HAWP 01300 Millipore), com poros de $0,45 \mu \mathrm{m}$. O volume de $100 \mu \mathrm{L}$ do filtrado foi injetado, imediatamente, no cromatógrafo a líquido.

Os folatos foram separados em sistema de eluição por gradiente, com $100 \%$ de solução aquosa de ácido acético (2 \%) a pH 2,8, chegando em 40 min a $76 \%$ de solução de ácido acético e $24 \%$ de acetonitrila, mantendo-se essa proporção até $45 \mathrm{~min}$. As condições iniciais foram retomadas e a coluna re-equilibrada durante $15 \mathrm{~min}$, antes da próxima injeção. A detecção foi feita por fluorescência e na região do UV (arranjo de diodos - DAD). Para THF, 5-metilTHF, 5formilTHF utilizou-se os comprimentos de onda $(\lambda)$ de $\lambda_{\text {excitacão }}$ de $290 \mathrm{~nm}$ e $\lambda_{\text {emissão }}$ de $360 \mathrm{~nm}$. Para o 10-formilAF utilizou-se o mesmo $\lambda_{\text {excitação }}$ e o $\lambda_{\text {emissão }}$ de $445 \mathrm{~nm}$. Já para o 10 -metilAF utilizou-se o $\lambda$ de $290 \mathrm{~nm}$, na região do UV. A identificação da vitamina foi feita por comparação dos tempos de retenção, obtidos com padrões analisados nas mesmas condições, co-cromatografia e pela comparação dos espectros de absorção. A pureza do pico foi determinada pelo sistema ploter disponível no software HP-Chemstation. A quantificação foi feita por padronização externa. As curvas de calibração foram construídas para as duas formas da vitamina encontradas, 5-metilTHF e 5-formilTHF. Para o 5-metilTHF as concentrações foram de 30, $80,160,240,330,650,1000 \mu \mathrm{g} / 100 \mathrm{~mL}$, já para o 5-formilTHF de $5,15,30,45,60 \mu \mathrm{g} / 100 \mathrm{~mL}$, sendo cada ponto, nos dois casos, representado pela média de três determinações.

\section{Validação da metodologia}

Testes de recuperação e repetibilidade foram realizados com as amostras analisadas, já que a metodologia aplicada foi desenvolvida para outro tipo de alimento e houve necessidade de adequação do processo de extração dos folatos. Limites de detecção e de quantificação também foram determinados para essas novas matrizes. 
Tabela 1. Recuperação dos padrões de folatos adicionados às amostras de brócolis

\begin{tabular}{lcccc}
\hline Folatos & Nível I & Recuperação(\%) & Nível II & Recuperação(\%) \\
\hline 5-metilTHF & $1,00 \mu \mathrm{g} / 100 \mathrm{~mL}$ & 96 & $0,50 \mu \mathrm{g} / 100 \mathrm{~mL}$ & 99 \\
5-formilTHF & $0,20 \mu \mathrm{g} / 100 \mathrm{~mL}$ & 98 & $0,10 \mu \mathrm{g} / 100 \mathrm{~mL}$ & 95 \\
10 -metilTHF & $0,10 \mu \mathrm{g} / 100 \mathrm{~mL}$ & 97 & $0,05 \mu \mathrm{g} / 100 \mathrm{~mL}$ & 94 \\
10 -formilTHF & $0,14 \mu \mathrm{g} / 100 \mathrm{~mL}$ & 97 & $0,07 \mu \mathrm{g} / 100 \mathrm{~mL}$ & 96 \\
THF & $0,20 \mu \mathrm{g} / 100 \mathrm{~mL}$ & 96 & $0,10 \mu \mathrm{g} / 100 \mathrm{~mL}$ & 97 \\
\hline
\end{tabular}

Os resultados são médias de cinco determinações, em duplicata.

\section{Recuperação de padrões}

Para a avaliação da exatidão do método, realizou-se teste de recuperação de padrões adicionados às amostras, em dois níveis diferentes de concentração. Esses valores foram escolhidos aleatoriamente. Para as análises foram utilizados $10,0 \mathrm{~g}$ de brócolis.

Para essas determinações, inicialmente, foi estabelecido o teor de folatos naturalmente presentes em brócolis. A concentração de folatos na amostra foi determinada através da média de 10 determinações. Posteriormente, foram adicionadas quantidades conhecidas dos folatos, seguindo-se, então, a metodologia. Para o cálculo da recuperação, de acordo com Rodriguez et al. ${ }^{25}$ utilizou-se a seguinte equação:

Recuperação $=\frac{(\text { Concentração encontrada }- \text { Concentração amostra })}{\text { Concentração adicionada }} \times 100 \%$

\section{Repetibilidade}

A avaliação desse parâmetro foi realizada através de 10 determinações nos níveis de concentração de folatos encontrados na matriz. A repetibilidade foi calculada de acordo com Caulcutt e Boddy $^{26}$ através da equação:

$\mathrm{r}=\mathrm{t} \sqrt{2 . \mathrm{sr}}$

$\mathrm{r}=$ repetibilidade; $\mathrm{sr}=$ estimativa do desvio padrão; $\mathrm{t}=$ de Student.

\section{Limites de detecção e quantificação}

O limite de detecção foi estimado por diluições sucessivas dos padrões de concentrações conhecidas das diferentes formas da vitamina, até a determinação da menor quantidade detectável, para cada uma delas, como sendo 3 vezes o valor da amplitude do ruído do equipamento $(\mathrm{S} / \mathrm{R} \geq 3){ }^{26} \mathrm{O}$ limite de quantificação foi considerado como sendo 10 vezes o limite de detecção. ${ }^{27}$

\section{Análise estatística}

Com a finalidade de se definir se existia ou não diferença significativa entre os valores obtidos para o teor de folatos, avaliado em brócolis cultivados de forma orgânica e tradicional, realizou-se teste $t$, utilizando o programa GraphPad Prism (versão 2.01).

\section{RESULTADOS E DISCUSSÃO}

\section{Validação da metodologia}

Na Tabela 1 estão apresentadas as taxas de recuperação obtidas. Os valores médios para as concentrações de folatos adicionadas variaram entre 94 e $99 \%$.

No ensaio de repetibilidade foram avaliados 5-metilTHF e 5formilTHF, as únicas formas de folatos encontradas nas amostras de brócolis. As faixas de repetibilidade esperadas, entre 10 determinações de folatos, em duplicata, estão dispostas na Tabela 2.
Observou-se que a maior diferença entre os valores obtidos nas análises foi menor que o valor de " $r$ " calculado, comprovando a boa repetibilidade do método aplicado.

Tabela 2. Repetibilidade nas determinações de 5-metilTHF e 5formilTHF em brócolis

\begin{tabular}{lccc}
\hline $\begin{array}{l}\text { Teor de } \\
\text { 5-MeTHF } \\
(\mu \mathrm{g} / 100 \mathrm{~g})\end{array}$ & $\begin{array}{c}\text { Repetibilidade } \\
(\mathrm{r})\end{array}$ & $\begin{array}{c}\text { Teor de } \\
\text { 5-ForTHF } \\
(\mu \mathrm{g} / 100 \mathrm{~g})\end{array}$ & $\begin{array}{c}\text { Repetibilidade } \\
(\mathrm{r})\end{array}$ \\
\hline 420,36 & & 6,45 & 3,00 \\
421,45 & 4,83 & 6,98 & \\
420,98 & & 5,74 & \\
423,89 & & 6,02 & \\
422,69 & & 5,73 & \\
421,87 & & 4,99 & \\
419,45 & & 6,12 & \\
423,96 & 5,27 & \\
423,36 & & 5,48 & \\
421,37 & & 6,14 & \\
$421,9 \pm 1,50,4 \% *$ & $5,9 \pm 0,610,2 \% *$ & \\
\hline
\end{tabular}

Limite de confiança de $95 \%(\mathrm{t}=2,78)$; Média dos valores \pm estimativa do desvio padrão, coeficiente de variação.

Os limites de detecção (LD) foram 5, 30, 30, 7 pg/mL, $5 \mathrm{ng} / \mathrm{mL}$ para 5-metilTHF, 5-formilTHF, 10-formilTHF, THF e 10-metilTHF, respectivamente. Os limites de quantificação foram considerados como sendo 10 vezes o LD.

\section{Etapa analítica}

Na Figura 1 apresenta o cromatograma obtido após a análise de folatos em brócolis. Os picos de 5-metilTHF e 5-formilTHF aparecem isolados com tempos de retenção de aproximadamente 25,7 e 28,6 min, respectivamente.

As curvas analíticas traçadas por padronização externa apresentaram boas linearidades nas faixas de concentração de 30-1000 $\mu \mathrm{g} / 100 \mathrm{~mL}$ e $5-60 \mu \mathrm{g} / 100 \mathrm{~mL}$, para 5-metilTHF e 5-formil-THF; os coeficientes de correlação obtidos foram 0,9987 e 0,9996 , respectivamente, conforme Figura 2.

\section{Influência do tipo de cultivo}

$\mathrm{Na}$ Tabela 3 estão apresentados os valores para o teor de 5metilTHF e 5-formilTHF obtidos após a análise de brócolis cultivados em sistema orgânico e convencional. Para o brócolis convencional a concentração de 5-metilTHF variou de 413,7 a 742,2 $\mu \mathrm{g} / 100 \mathrm{~g}$ (em média 552,0 $\mu \mathrm{g} / 100 \mathrm{~g}$ ) e para 5-formilTHF de 4,8 a 12,8 $\mu \mathrm{g} / 100$ $\mathrm{g}$ (em média, 7,8 $\mu \mathrm{g} / 100 \mathrm{~g}$ ). O teor de 5-metilTHF e 5-formilTHF em brócolis orgânico foi de 954,0 a 1739,7 $\mu \mathrm{g} / 100 \mathrm{~g}$ (em média, 1324,9 $\mu \mathrm{g} / 100 \mathrm{~g}$ ) e de 7,9 a 13,6 $\mu \mathrm{g} / 100 \mathrm{~g}$ (em média, 10,2 $\mu \mathrm{g} / 100 \mathrm{~g}$ ), respectivamente. $\mathrm{O}$ tratamento estatístico indicou haver diferença sig- 


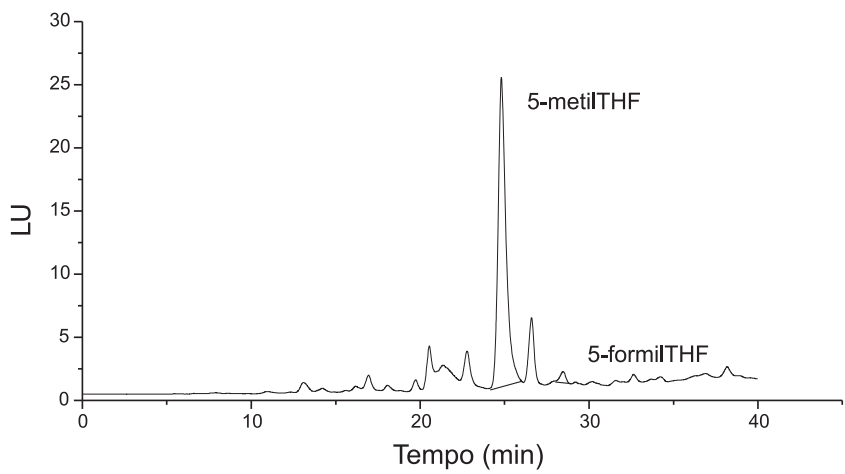

Figura 1. Perfil cromatográfico do extrato de brócolis. Coluna MicrosorbMV, ODS-2, $5 \mu \mathrm{m}, 250$ X 4,6 mm. Fase móvel (0,5 mL/min): 100\% de solução aquosa de ácido acético (2\%) no início da corrida, chegando em 40 min a $76 \%$ de solução de ácido acético e $24 \%$ de acetonitrila. Detecção por fluorescência $\left(\lambda_{\text {exc. }} 290 \mathrm{~nm}\right.$ e $\left.\lambda_{\text {emis. }} 360 \mathrm{~nm}\right)$

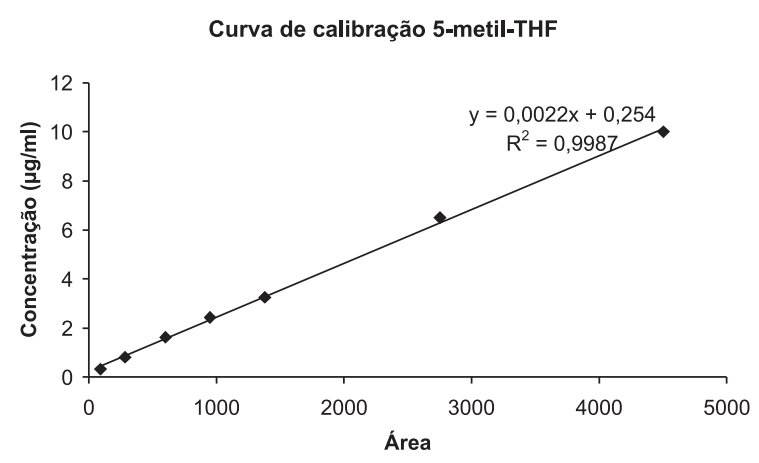

Curva de calibração 5-formilTHF

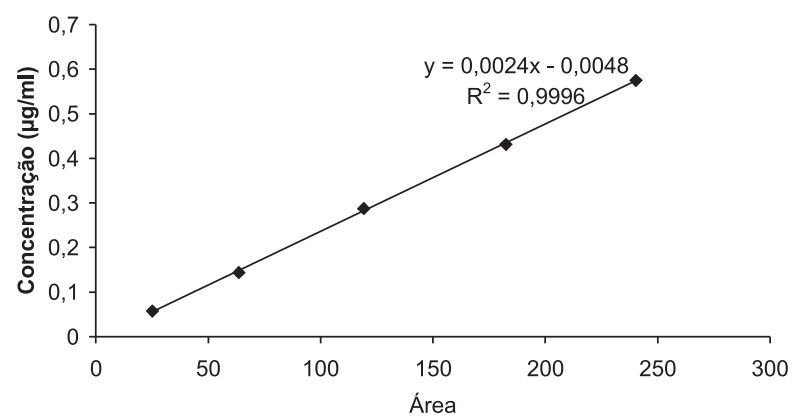

Figura 2. Curvas analíticas utilizadas na quantificação de 5-metilTHF e 5formilTHF

nificativa no teor de folatos totais, entre os diferentes tipos de cultivos. Os valores obtidos para 5-metilTHF foram significativamente superiores nos brócolis orgânicos, já a concentração de 5-formilTHF, encontrada nas diferentes amostras, não diferiu significativamente em relação ao tipo de cultivo.

Dessa forma, para as amostras analisadas no trabalho, verificou-se que o vegetal cultivado por agricultura orgânica apresentou maior teor de folatos quando comparado ao produzido por cultivo tradicional. Essa constatação indica maior qualidade nutricional de brócolis orgânico, em relação aos folatos, para as amostras avaliadas.

Não foram encontrados em publicações científicas trabalhos semelhantes para comparação dos dados. Foi possível, entretanto, verificar-se que as amostras de brócolis analisadas apresentaram concentração da vitamina muito superior em relação às determinações de folatos no mesmo alimento, divulgadas em outros traba-
Tabela 3. Concentração de folatos em brócolis cultivados em sistema tradicional e orgânico

\begin{tabular}{|c|c|c|c|c|c|}
\hline \multirow{2}{*}{\multicolumn{2}{|c|}{ Cultivo/Lote }} & \multicolumn{2}{|c|}{$\begin{array}{c}\text { Teor de } \\
\text { 5-metilTHF } \\
(\mu \mathrm{g} / 100 \mathrm{~g})\end{array}$} & \multicolumn{2}{|c|}{$\begin{array}{c}\text { Teor de } \\
\text { 5-formilTHF } \\
(\mu \mathrm{g} / 100 \mathrm{~g})\end{array}$} \\
\hline & & $\mathrm{M} \pm \mathrm{DP}$ & $\% \mathrm{CV}$ & $\mathrm{M} \pm \mathrm{DP}$ & $\% \mathrm{CV}$ \\
\hline \multirow{5}{*}{\multicolumn{2}{|c|}{$\begin{array}{r}1 \\
2 \\
3 \\
4 \\
5\end{array}$}} & $413,7 \pm 6,3$ & 1,5 & $10,7 \pm 0,7$ & 6,5 \\
\hline & & $482,7 \pm 4,7$ & 1,0 & $12,8 \pm 1,0$ & 7,8 \\
\hline & & $742,2 \pm 8,4$ & 1,1 & $4,8 \pm 0,5$ & 10,4 \\
\hline & & $441,7 \pm 4,6$ & 1,0 & $6,1 \pm 0,4$ & 6,6 \\
\hline & & $679,9 \pm 4,0$ & 0,6 & $4,8 \pm 0,7$ & 14,6 \\
\hline \multicolumn{2}{|c|}{ Média dos lotes } & $552,0 \pm 148,8 \mathrm{a}$ & 27,0 & $7,8 \pm 3,7 \mathrm{a}$ & 77,0 \\
\hline \multirow[t]{5}{*}{ Orgânico } & 1 & $954,0 \pm 6,5$ & 0,7 & $12,5 \pm 0,8$ & 6,4 \\
\hline & 2 & $1265,3 \pm 10,6$ & 0,8 & $13,6 \pm 0,5$ & 3,7 \\
\hline & 3 & $1706,0 \pm 16,4$ & 0,1 & $7,9 \pm 0,4$ & 5,1 \\
\hline & 4 & $1739,7 \pm 10,2$ & 0,6 & $8,7 \pm 0,7$ & 8,1 \\
\hline & 5 & $959,6 \pm 8,1$ & 0,8 & $8,3 \pm 1,0$ & 10,2 \\
\hline \multicolumn{2}{|c|}{ Média dos lotes } & $1324,9 \pm 384,7 b$ & 29,0 & $10,2 \pm 2,6 a$ & 25,5 \\
\hline
\end{tabular}

Valores são médias de determinações em triplicata. $\mathrm{M} \pm \mathrm{DP}$ : média dos valores \pm estimativa do desvio padrão. \%CV: \% coeficiente de variação. Letras diferentes na mesma coluna representam haver diferença significativa $(\mathrm{p}<0,05)$.

lhos, conforme apresentado no Quadro 1. Essa observação, provavelmente, é devida às diferentes condições de solo e clima, envolvidas no cultivo do vegetal.

Influência do cozimento em água

Para a avaliação da estabilidade dos folatos após o cozimento de amostras de brócolis em água, inicialmente, determinou-se a umidade $(\%)$ referente a cada lote analisado no trabalho, conforme valores apresentados na Tabela 4. Observou-se que a umidade média para os vegetais in natura foi de $87 \%$. Para o brócolis cozido, $91 \%$, indicando haver incorporação de água após o cozimento.

Tabela 4. Determinação da umidade das amostras de brócolis cozidas e in natura

\begin{tabular}{lccc}
\hline \multirow{2}{*}{ Brócolis/Lotes } & \multicolumn{2}{c}{ Umidade $(\%)$} \\
& & $\mathrm{M} \pm \mathrm{DP}$ & $\% \mathrm{CV}$ \\
\hline In natura & 1 & $86,2 \pm 0,9$ & 1,0 \\
& 2 & $86,0 \pm 0,2$ & 0,2 \\
& 3 & $87,5 \pm 0,1$ & 0,1 \\
& 4 & $88,0 \pm 0,1$ & 0,1 \\
Média entre lotes & $87,3 \pm 0,5$ & 0,6 \\
\hline Cozido & 1 & $87,0 \pm 0,9$ & 1,0 \\
& 2 & $91,2 \pm 0,1$ & 0,1 \\
& 3 & $91,1 \pm 0,1$ & 0,1 \\
& 4 & $90,0 \pm 0,4$ & 0,4 \\
& 5 & $90,6 \pm 0,1$ & 0,1 \\
\multicolumn{2}{l}{ Média entre lotes } & $91,8 \pm 0,3$ & 0,3 \\
\hline
\end{tabular}

Valores são médias de determinações em triplicatas. $\mathrm{M} \pm \mathrm{DP}$ : média dos valores \pm estimativa do desvio padrão. \%CV: \% coeficiente de variação.

Nos lotes de brócolis avaliados, conforme já mencionado, apenas 5-metilTHF e 5-formilTHF foram detectados. As concentrações das duas formas da vitamina, obtidas em cinco diferentes lotes de brócolis (in natura e cozido) e na água de cozimento, estão apresen- 
tadas na Tabela 5. Observando-se os valores nota-se que aproximadamente $53 \%$ do teor de 5-metilTHF e 5-formilTHF, encontrados em brócolis in natura, passaram para a água de cozimento. Essa constatação está de acordo com as conclusões de Leichter et al., ${ }^{21}$ de que a maior parte da vitamina é perdida por lixiviação, em vegetais submetidos ao cozimento em água.

Na Tabela 6 estão apresentados os valores obtidos para os mesmos lotes, em base seca e a porcentagem de perda, das duas formas da vitamina após o cozimento em água. Observa-se que as concentrações de 5-metilTHF variaram de 2997,8 a 5937,68 $\mu \mathrm{g} / 100 \mathrm{~g}$ e de 931,8 a $1763,0 \mu \mathrm{g} / 100 \mathrm{~g}$, para brócolis in natura e cozido, respectivamente. Para o 5-formil a concentração oscilou entre 37,8 a 91,4 $\mu \mathrm{g} / 100 \mathrm{~g}$ e 12,0 a 24,7 $\mu \mathrm{g} / 100 \mathrm{~g}$, para as mesmas amostras. Observou-se, inicialmente, uma grande variação entre os lotes, tanto para 5-metilTHF quanto para 5-formilTHF devida, provavelmente, às diferentes condições edafoclimáticas durante o cultivo e grau de maturação, já que a síntese de folatos pelos vegetais é diretamente influenciada por esses fatores.

Quanto à porcentagem de perda das diferentes formas da vitamina, verificou-se que para o 5-metilTHF e para o 5-formilTHF as perdas médias foram de aproximadamente 67 e $70 \%$, valores superiores aos declarados por Klein et al., ${ }^{23}$ Leichter et al. ${ }^{21}$ e Stea et $a l .{ }^{14}$ que observaram perdas de 50, 62 e $24,5 \%$, respectivamente.
A solubilidade dos folatos em água é uma característica que influencia fortemente em sua perda, principalmente por lixiviação, quando ocorre contato direto do vegetal com a água em ebulição. Os resultados obtidos nesse estudo revelam que as amostras de brócolis analisadas apresentaram alto teor de folatos, entretanto, as perdas ocorridas durante o processo de cozimento em água, devem ser consideradas nos inquéritos de consumo alimentar, instrumentos necessários em estudos epidemiológicos.

\section{CONCLUSÕES}

O método utilizado apresentou eficiência, sendo considerado adequado para a determinação de folatos em brócolis, visto que todos os parâmetros avaliados na sua validação mostraram resultados positivos.

A avaliação da influência do tipo de cultivo na concentração das duas diferentes formas de folatos, para as amostras disponíveis comercialmente, analisadas neste trabalho, permitiu concluir, de forma preliminar, que brócolis cultivados de forma orgânica apresentaram maior quantidade de folatos, quando se compara o teor da vitamina, para o mesmo vegetal, cultivado de forma convencional. Sugere-se que outros trabalhos sejam realizados, utilizando-se o controle das etapas de produção e pós-colheita, além de um número maior de amostras.

Tabela 5. Concentração de folatos em brócolis in natura e cozido e na água de cozimento

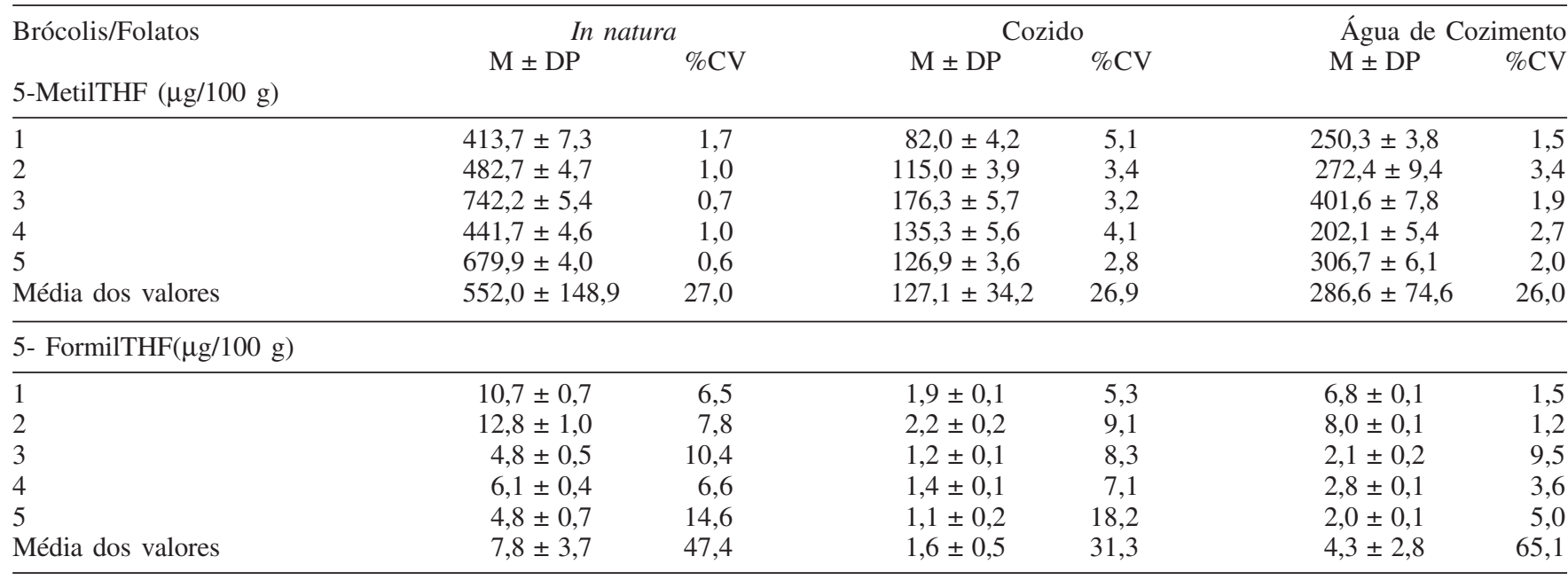

Valores são médias de determinações em triplicata. $\mathrm{M} \pm \mathrm{DP}$ : média dos valores \pm estimativa do desvio padrão. \%CV: \% coeficiente de variação.

Tabela 6. Folatos em brócolis, em base seca, e porcentagem de perda após cozimento

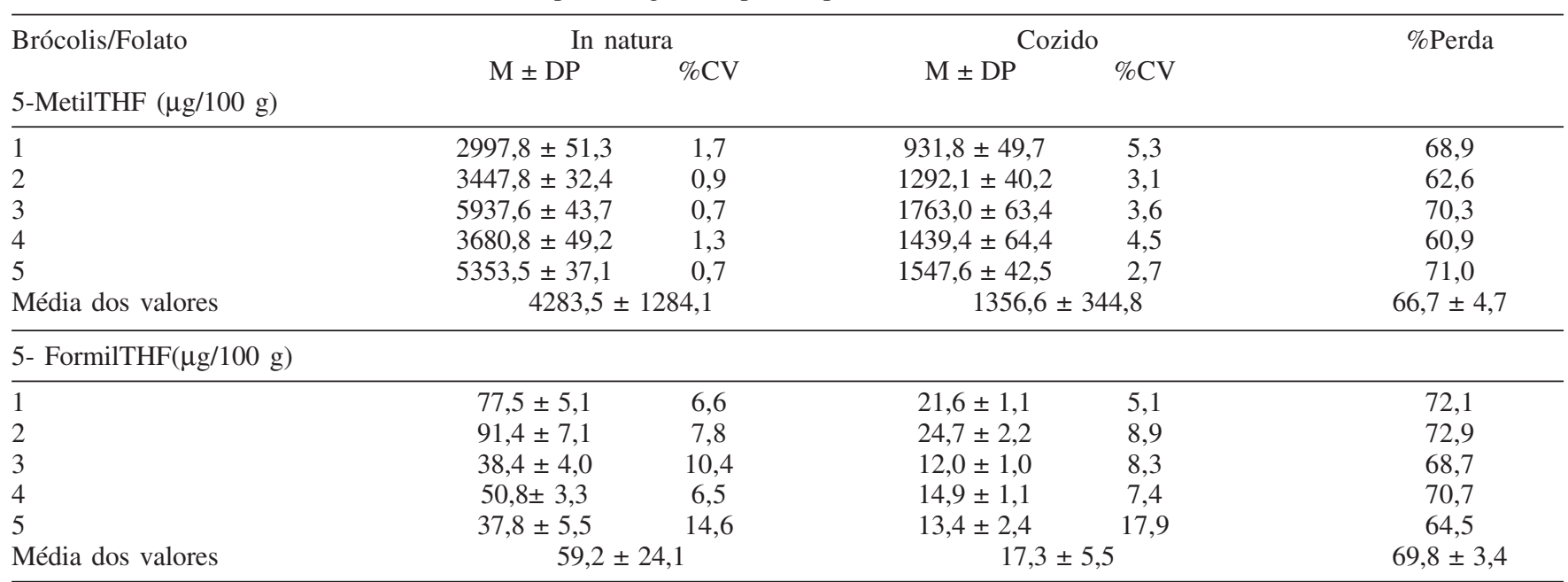

Valores são médias de determinações em triplicata. $\mathrm{M} \pm \mathrm{DP}$ : média dos valores \pm estimativa do desvio padrão. \%CV: \% coeficiente de variação. 
Observando-se os altos teores de 5-metilTHF e 5-formilTHF encontrados nos lotes de brócolis avaliados, pôde-se concluir que esse vegetal pode ser considerado uma excelente fonte da vitamina. Entretanto, o processo de cozimento em água acarretou em consideráveis perdas dos folatos, por lixiviação, indicando ser importante incentivar o aproveitamento da água de cozimento, a fim de que uma maior quantidade de folatos possa ser ingerida.

\section{REFERÊNCIAS}

1. Czeizel, A. E.; Dudás, I.; N. Engl. J. Med. 1992, 327, 1832.

2. Shaw, G. M.; Schaffer, D.; Velie, E. M.; Morland, K.; Harris, J. A.; Epidemiology 1995, 6, 219.

3. Eichholzer, M.; Tönz, O.; Lancet 2006, 367, 1352.

4. Scholl, T. O.; Hediger, M. L.; Schall, J. L.; Khoo, C. S.; Fisher, R. L.; Am. J. Clin. Nutr. 1996, 63, 520.

5. Giovannucci, E.; Stampfer, M. J.; Colditz, G. A.; Hunter, D. J.; Fuchs, C.; Rosner, B. A.; Speitzer, F. E.; Wilett, W. C.; Annals of Internal Medicine 1995, 129, 517.

6. Robinson, K.; Arheart, K.; Refsum, H.; Brattström, L.; Boers, G.; Ueland, P.; Rubba, P.; Palma-Reis, R.; Meleasy, R.; Daly, L.; Witteman, J.; Graham, I.; Circulation 1998, 97, 437.

7. Verhoff, P.; Stampfer, M. J.; Buring, J. E.; Gaziano, J. M.; Allen, R. H.; Stabler, S. P.; Reynolds, R. S.; Kok, F. J.; Hennekens, C. H.; Willett, W. C.; Am. J. Epidemiol. 1996, 143, 845.

8. Clarke, R.; Smith, D.; Jobst. K. A.; Refsum, H.; Sutton, L.; Ueland, P. M.; Arch. Neurol. 1998, 55, 1449.

9. Riggs, K. M.; Apiro, A. III; Tucker, K.; Rush, D.; Am. J. Clin. Nutr. 1996, $63,306$.
10. Gregory III, J. F.; Adv. Food Nutr. Res. 1989, 3, 1.

11. Carl, G. F.; Hudson, F. Z.; McGuire, B. S.; J. Nutr. 1995, 125, 2096

12. Wagner, C. Em Folate in Health and Disease; Bailey, L., ed.; Marcel Dekker: New York. 1995, p. 23.

13. Scott, J.; Rébeille, F.; Fletcher, J.; J. Sci. Food Agric. 2000, 80, 795.

14. Stea, T. H.; Johansson, M.; Jägerstad, M.; Frolich, W.; Food Chem. 2007, $101,1095$.

15. Iwatani, Y.; Arcot, J.; Shrestha, A. K.; J. Food Comp. Anal. 2003, 16, 37.

16. Konings, E. J. M.; Roomans, H. H. S.; Dorant, E.; Goldbohm, R. A.; Saris, W. H. M.; Brandt, P. A.; Am. J. Clin. Nutr. 2001, 73, 765.

17. Vahteristo, L. T.; Ollilainen, V.; Varo, P.; J. AOAC Int. 1997, 80, 373.

18. DeSouza, S. C.; Eitenmiller, R. R.; J. Food Sci. 1986, 51, 526.

19. Mullin, W. J.; Wood, D. F.; Howsam, S. G.; Nutr. Reports Int. 1982, $26,7$.

20. Leichter, J.; Landymore, A. F.; Krumdieck, C. L.; Am. J. Clin. Nutr. 1979, 32, 92.

21. Leichter, J.; Switzer, V. P.; Landymore, A. F.; Nutr. Reports Int. 1978, 18, 475.

22. Leskova, E.; Kubíková, J.; Kaváciková, E.; Kosická, M.; Porubská, J.; Holciková, K. J.; Food Comp. Anal. 2006, 19, 252.

23. Klein, B. P.; Lee, H. C.; Reynolds, P. A.; Wangles, N. C.; J. Food Sci. 1979, $46,286$.

24. Catharino, R. R.; Godoy, H. T.; Lima-Pallone J. A.; Quim. Nova 2006, 29, 972.

25. Rodriguez, L. C.; Campana, A. M. G.; Barrero, F. A.; Linares, C. J.; Ceba, M. R.; J. AOAC Int. 1995, 78, 471.

26. Caulcutt, R.; Boddy, R.; Statistic for Analytical Chemists, $1^{\text {st }}$. ed., Chapman and Hall: Londres, 1983.

27. Ribani, M.; Bottoli, C. B. G.; Collins, C. H.; Jardim, I. C. S. F.; Melo, L. F. C. M.; Quim. Nova 2004, 27, 771. 